\title{
HIGH EFFICIENCY ALN/GAN HEMTS FOR Q-BAND APPLICATIONS WITH AN IMPROVED THERMAL DISSIPATION*
}

\author{
Riad Kabouche*, Romain Pecheux, Kathia Harrouche, Etienne Okada, and Farid Medjdoub ${ }^{\dagger}$ \\ Institut d'Electronique, de Microélectronique et de Nanotechnologie, University Lille, Avenue Poincaré, \\ Villeneuve d'Ascq, France \\ "riad.kabouche@ed.univ-lille1.fr; ${ }^{*}$ farid.medjdoub@univ-lille.fr \\ Joff Derluyn, Stefan Degroote, Marianne Germain \\ EpiGaN company, Kempische Steenweg 293 \\ Hasselt, Belgique \\ Filip Gucmann, Callum Middleton, James W. Pomeroy, Martin Kuball \\ H. H Wills Physics Laboratory, University of Bristol, BS8 1TL \\ Bristol, United Kingdom \\ Received Day Month Year \\ Revised Day Month Year
}

\begin{abstract}
In this paper, we demonstrate Q-band power performance of carbon doped AlN/GaN high electron mobility transistors (HEMTs) using a deep sub-micrometer gate length $(120 \mathrm{~nm})$. With a maximum drain current density $\mathrm{I}_{\mathrm{D}}$ of $1.5 \mathrm{~A} / \mathrm{mm}$ associated to a high electron confinement and an extrinsic transconductance $\mathrm{g}_{\mathrm{m}}$ of $500 \mathrm{mS} / \mathrm{mm}$, this structure shows excellent electrical characteristics. A maximum oscillation frequency $\mathrm{f}_{\max }$ of $242 \mathrm{GHz}$ has been observed As a result, a state-of-the-art combination at $40 \mathrm{GHz}$ of output power density $\left(\mathrm{P}_{\mathrm{OUT}}=7 \mathrm{~W} / \mathrm{mm}\right)$ and power added efficiency $(\mathrm{PAE})$ of $52 \%$ up to $\mathrm{V}_{\mathrm{DS}}=25 \mathrm{~V}$ has been obtained. The achievement of such outstanding performance is attributed to the reduced thermal resistance $\left(\mathrm{R}_{\mathrm{TH}}\right)$ as compared to the commonly used double heterostructure by means of Raman thermography.
\end{abstract}

Keywords: High electron mobility transistors (HEMTs), Double heterostructure field effect transistor (DHFET), GaN, Raman thermography, output power density ( $\left.\mathrm{P}_{\text {OUT }}\right)$, power added efficiency (PAE).

\section{Introduction}

The requirements for the emerging wireless communication systems such as 5G significantly increases the need for compact solid-state high power amplification based on gallium nitride $(\mathrm{GaN})$ material. Achieving both high power-added-efficiency (PAE) and output-power-density ( $\left.\mathrm{P}_{\mathrm{OUT}}\right)$ in the millimeter-wave range represents currently one of the key goals for the GaN technology. Indeed, higher PAE not only saves electrical power usage but also can reduce the size and cost of high power amplifiers (HPAs), due to the lower amount of heat dissipated. For instance, in space applications, the traveling wave tube amplifiers (TWTA) are still commonly used, because of the high PAE while

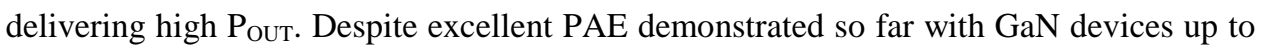


Ka band [1]-[5], a limited set of data in the Q band $(40 \mathrm{GHz})$ and above are available. As shown by HRL laboratory [6],[7] the double heterostructure field effect transistor (DHFET) using an AlGaN back barrier allowed combining a high electron confinement with high frequency performance together with low trapping effects [8]-[14]. However, $\mathrm{AlGaN}$ alloys have the drawback to provide much lower thermal conductivity than the binaries GaN or AlN [15], which in turn causes an increase in the peak channel temperature during operation [16]. Compared to Fe doped GaN buffers, carbon-doped HEMT structures show lower memory effects [17], lower risk of diffusion and the elimination of contamination risks when used in Si CMOS-based foundries. That is why, this structure is widely used for high voltage power applications. In this work, a carbon-doped HEMT structure [19], using a $0.12 \mu \mathrm{m}$ gate technology has been evaluated and compared to a DHFET [20] with the aim of pushing the bias operation in the millimeter-wave range while maintaining a reduced junction temperature.

\section{Device Fabrication}

The AlN/GaN heterostructures were grown by metal organic chemical vapor deposition (MOCVD) on 4 in. SiC substrates. The HEMT structure consists of a transition layer to GaN, a $1 \mu \mathrm{m}$-thick carbon-doped GaN buffer layer followed by a $150 \mathrm{~nm}$ thick un-doped GaN channel, a $4 \mathrm{~nm}$ ultrathin AlN barrier layer and a 10-nm-thick in situ $\mathrm{S}_{\mathrm{i} 3} \mathrm{~N}_{4}$ cap layer (Fig. 1). The in-situ SiN layer is used both as early passivation as well as to prevent strain relaxation [21]-[23]. The channel thickness has been chosen with respect to the trade-off between the electron confinement and the trapping effects. In the second structure called DHFET, the GaN buffer layer is replaced by a $1 \mu \mathrm{m}$-thick $\mathrm{Al}_{0.08} \mathrm{Ga}_{0.92} \mathrm{~N}$ layer as shown in Figure 1. Room temperature Hall measurements showed high electron sheet concentrations of $1.8 \times 10^{13}$ and $1.6 \times 10^{13} \mathrm{~cm}^{-2}$ with an electron mobility of about $1100 \mathrm{~cm}^{2} \mathrm{~V}^{-1} \mathrm{~s}^{-1}$ in the HEMT and DHFET heterostructures, respectively. The device fabrication details can be found in [20]. Ohmic contact resistance (Rc) extracted from linear transmission line method (TLM) was as low as $0.3 \Omega . \mathrm{mm}$ for both heterostructures. A $0.12 \mu \mathrm{m} \mathrm{Ni} / \mathrm{Au} \mathrm{T}$ gate length was defined by e-beam lithography (see Fig. 1). The gate-source and gate drain spacing were 0.3 and $2 \mu \mathrm{m}$, respectively, and the unit device width was $50 \mu \mathrm{m}$.
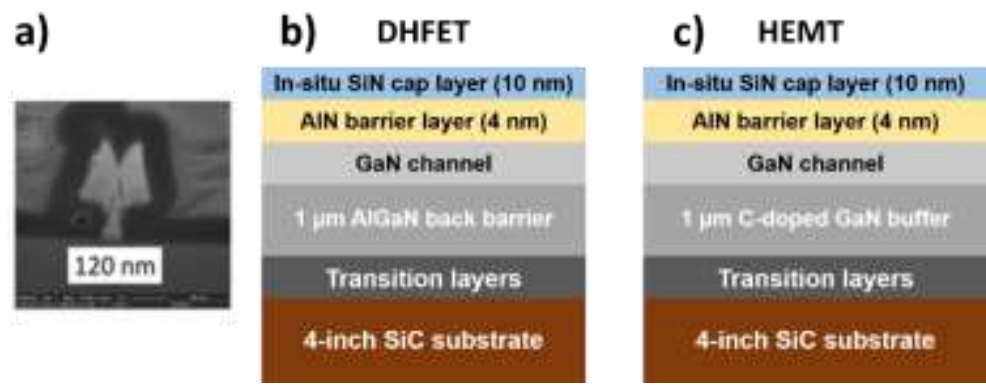

Fig. 1. a) FIB view of the $0.12 \mu \mathrm{m}$ T-gate and schematic cross section of b) DHFET and c) C-doped HEMT.

\section{DC AND SMALL SIGNAL CHARACTERIZATIONS}


DC characterizations have been performed with a Keysight A2902A parameter analyzer. Fig. 2 shows some typical $I_{D}-V_{D S}$ characteristics for both structures. The gate source voltage was swept from $-6 \mathrm{~V}$ to $+2 \mathrm{~V}$ with a step of $0.5 \mathrm{~V}$. For the DHFET, a maximum drain current density $\left(\mathrm{I}_{\text {Dmax }}\right)$ of $1.3 \mathrm{~A} / \mathrm{mm}$ is observed. The devices based on the HEMT structure deliver a higher $\mathrm{I}_{\mathrm{Dmax}}$ of $1.5 \mathrm{~A} / \mathrm{mm}$ under the same conditions reflecting the higher carrier concentration.
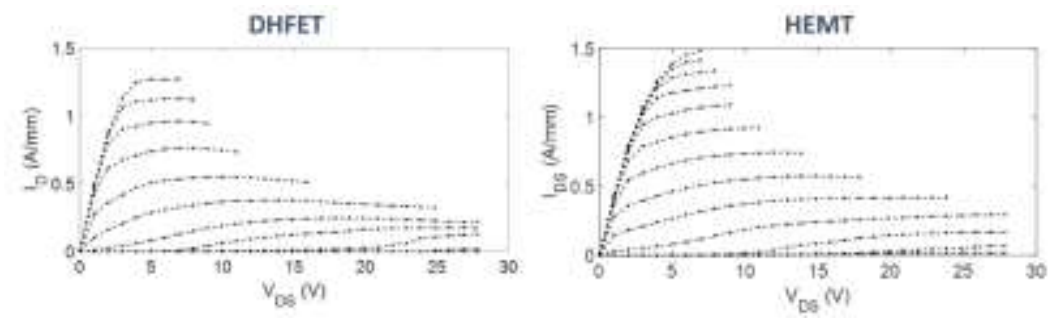

Fig. 2. Output characteristics of a $2 \times 50 \mu \mathrm{m}$ AlN/GaN DHFET and HEMT

The transfer characteristics of both structures at $\mathrm{V}_{\mathrm{DS}}=6,8$ and $10 \mathrm{~V}$ appear in Fig. 3 . Excellent device pinch-off behavior was obtained, which is illustrated by the low off-state leakage current below $10 \mu \mathrm{A} / \mathrm{mm}$ and the high breakdown voltages of $80 \mathrm{~V}$ and $110 \mathrm{~V}$ for the HEMT and DHFET structures, respectively. A low threshold voltage shift as a function of $\mathrm{V}_{\mathrm{DS}}$ is also observed in both cases. This confirms that a good electron confinement can be also obtained without the insertion of an AlGaN back barrier, despite the use of short gate lengths $(<150 \mathrm{~nm})$. In addition, a slightly higher extrinsic transconductance is observed for the HEMT structure with a $\mathrm{g}_{\mathrm{m}}$ around $500 \mathrm{mS} / \mathrm{mm}$ at $\mathrm{V}_{\mathrm{DS}}=10 \mathrm{~V}$ against 470 $\mathrm{mS} / \mathrm{mm}$ at $\mathrm{V}_{\mathrm{DS}}=10 \mathrm{~V}$ for the DHFET. The current-gain and power-gain cut-off frequencies are extracted from the scattering $(\mathrm{S})$ parameters using Rhode and Schwarz ZVA67GHz network analyzer at $\mathrm{V}_{\mathrm{DS}}=20 \mathrm{~V}$. The quiescent current bias point has been varied around the peak transconductance so that the maximum frequency performances are extracted. The DHFET yields a $\mathrm{f}_{\mathrm{T}}=45 \mathrm{GHz}$ and $\mathrm{f}_{\max }=235 \mathrm{GHz}$, while slightly better RF performances are achieved for the HEMT with $\mathrm{f}_{\mathrm{T}}=60 \mathrm{GHz}$ and $\mathrm{f}_{\max }=242 \mathrm{GHz}$ (see Fig. 4). This indicates that we may benefit from a shorter effective gate length with the HEMT structure at such high bias. Fig. 5 show the pulsed I-V characteristics performed with a quiescent drain voltage $\left(\mathrm{V}_{\mathrm{Q}, \mathrm{DS}}\right)$ up to $25 \mathrm{~V}$ at $\mathrm{V}_{\mathrm{GS}}=+1 \mathrm{~V}$ (all pulse conditions are described on Fig. 5). For both structures, a low gate-lag and a rather similar drain-lag of about $20 \%$ are observed.
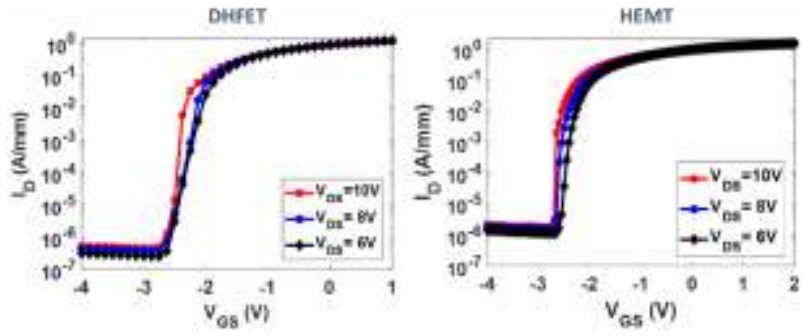

Fig. 3. Transfer characteristics at $\mathrm{V}_{\mathrm{DS}}=6,8,10 \mathrm{~V}$ of a $2 \times 50 \mu \mathrm{m}$ AlN/GaN DHFET and HEMT.
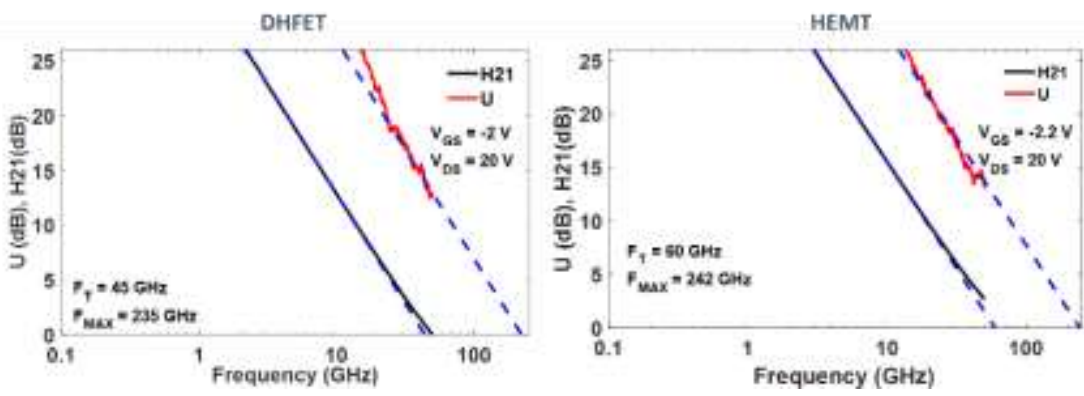
Fig. 4. RF performance of a $2 \times 50 \mu \mathrm{m}$ AlN/GaN DHFET and HEMT.
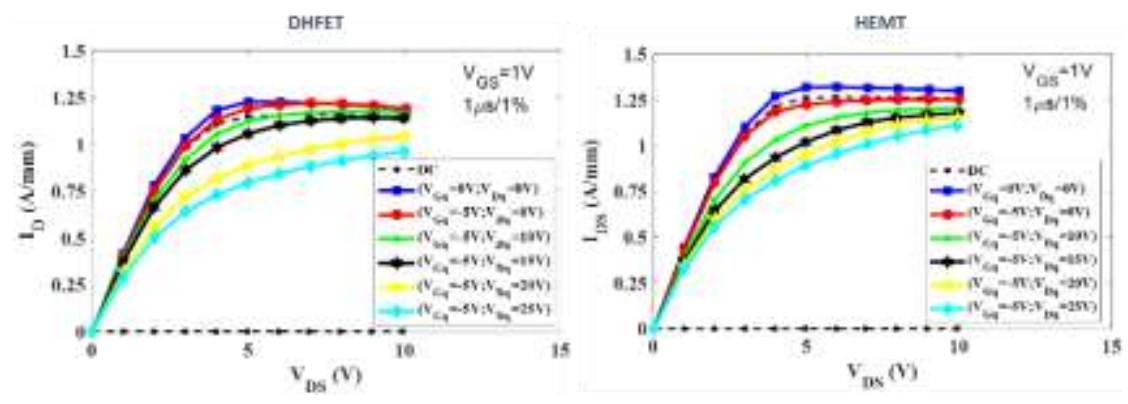

Fig. 5. Pulsed I-V characteristics of a $2 \times 50 \mu \mathrm{m}$ AlN/GaN DHFET and HEMT.

\section{LARGE SIGNAL CHARACTERIZATION AT $40 \mathrm{GHZ}$}

Large signal characterizations have been realized on a nonlinear vector network analyzer system (Keysight Network Analyser PNA-X, N5245A-NVNA) capable of on-wafer large signal device characterization up to the Q-band in continuous and pulsed mode. Further details can be found in [24]. On both structures, load-pull measurements have been carried out in pulsed mode ( $1 \mu \mathrm{s}$ width and $1 \%$ duty cycle). It can be stressed that the same measurement conditions with a drain current density of $100 \mathrm{~mA} / \mathrm{mm}$ has been used for the HEMTs and DHFETs. Fig. 6 shows the pulsed power performance of a $2 \times 25 \mu \mathrm{m}$ AlN/GaN HEMT at $40 \mathrm{GHz}$ with $\mathrm{V}_{\mathrm{DS}}=15 \mathrm{~V}, 20 \mathrm{~V}$, and $25 \mathrm{~V}$. The rather low gain is due to the biasing conditions in deep class $\mathrm{AB}$. A high saturated $\mathrm{P}_{\text {OUT }}$ of $7 \mathrm{~W} / \mathrm{mm}$ was achieved with a peak PAE of $52 \%$ (corresponding to a drain efficiency of $74 \%$ ) associated to a linear power gain above $8 \mathrm{~dB}$. Furthermore, at $\mathrm{V}_{\mathrm{DS}}=10 \mathrm{~V}$ a PAE as high as $56 \%$ (corresponding to a drain efficiency of $75 \%$ ) combined with an output power density of $1.6 \mathrm{~W} / \mathrm{mm}$ have been reached. Similarly, the pulsed power performance of a $2 \times 25 \mu \mathrm{m}$ DHFET structure at 40 $\mathrm{GHz}$ is shown in Fig. 7. The output power density evolves linearly as a function of the drain bias (see Figure 8 ) up to $\mathrm{V}_{\mathrm{DS}}=25 \mathrm{~V}$ for both structures reflecting the high material quality and associated processing. It is worth noting that the HEMT structure shows the ability to deliver a PAE above $50 \%$ up to $\mathrm{V}_{\mathrm{DS}}=25 \mathrm{~V}$.

For the DHFET, an increasing evolution of the PAE up to $\mathrm{V}_{\mathrm{DS}}=20 \mathrm{~V}$ is observed, reaching more than $45 \%$ associated to an output power density of $5.1 \mathrm{~W} / \mathrm{mm}$ at $\mathrm{V}_{\mathrm{DS}}=20 \mathrm{~V}$. Nevertheless, at $\mathrm{V}_{\mathrm{DS}}=25 \mathrm{~V}$ a strong degradation is observed with a PAE decreasing to $35 \%$. It can be noticed that no device degradation (Fig. 9) is observed in both cases (such as an eventual gate leakage current increase) subsequent to the number of pulsed power 
sweeps. Thus, the significant drop of the PAE at $V_{D S}=25 \mathrm{~V}$ is attributed to the self-heating, despite the pulsed mode. In turn, the $1 \mu \mathrm{s}$ pulse width is large enough to allow the increase of the junction temperature at such a high voltage within the DHFET structure. As can be seen from the benchmark in Fig. 10, the achieved PAE / P Out combination at $40 \mathrm{GHz}$ compares favorably to the state-of-the-art, especially for power densities above $5 \mathrm{~W} / \mathrm{mm}$.

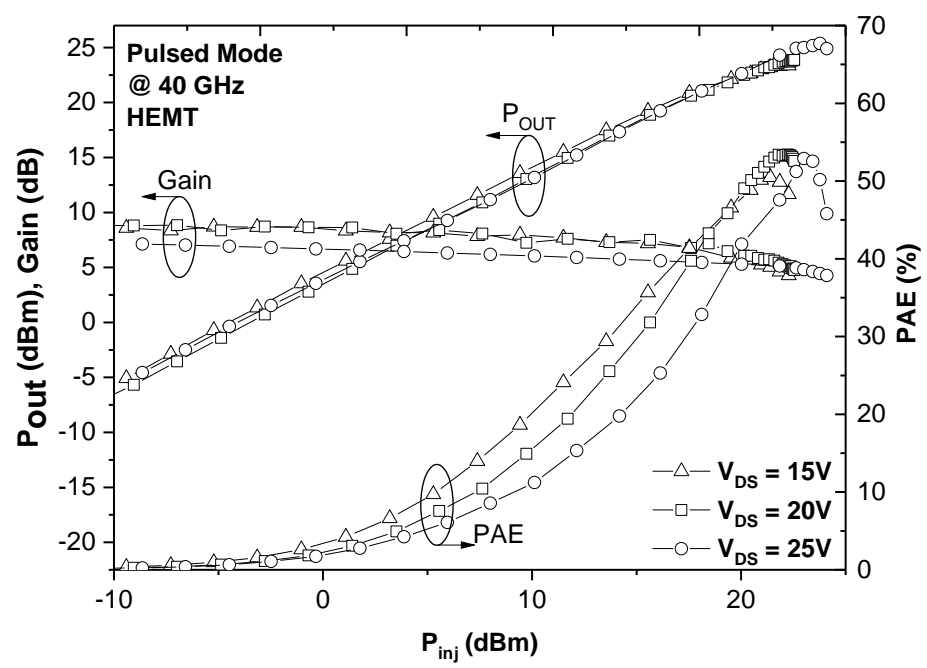

Fig. 6. Pulsed power performance of a $2 \times 25 \mu \mathrm{m}$ AlN/GaN HEMT at $40 \mathrm{GHz}$ with $\mathrm{V}_{\mathrm{DS}}=15,20,25 \mathrm{~V}$.

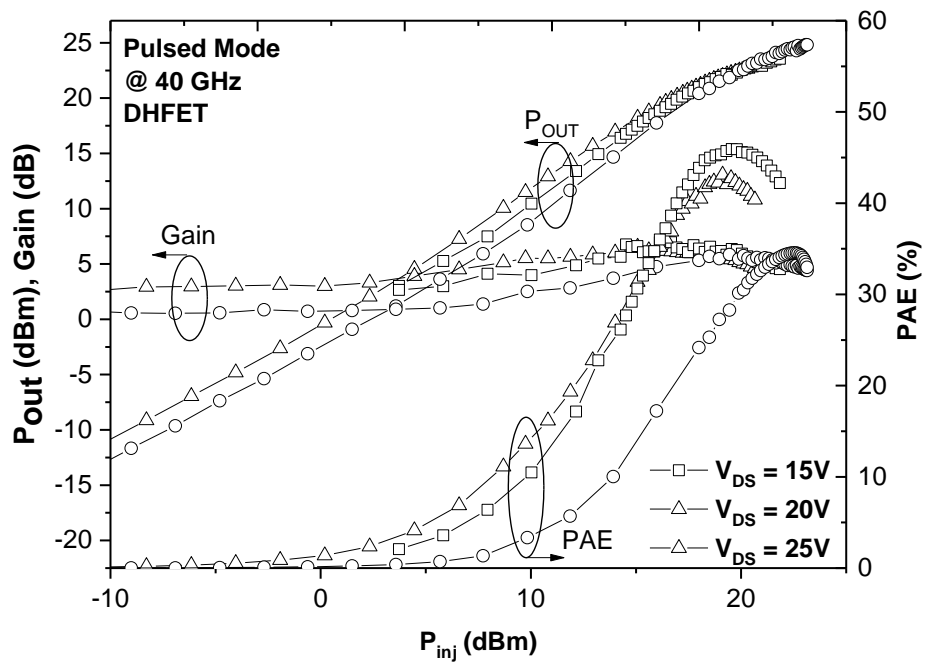

Fig. 7. Pulsed power performance of a $2 \times 25 \mu \mathrm{m}$ AlN/GaN DHFET at $40 \mathrm{GHz}$ with $\mathrm{V}_{\mathrm{DS}}=15,20,25 \mathrm{~V}$.

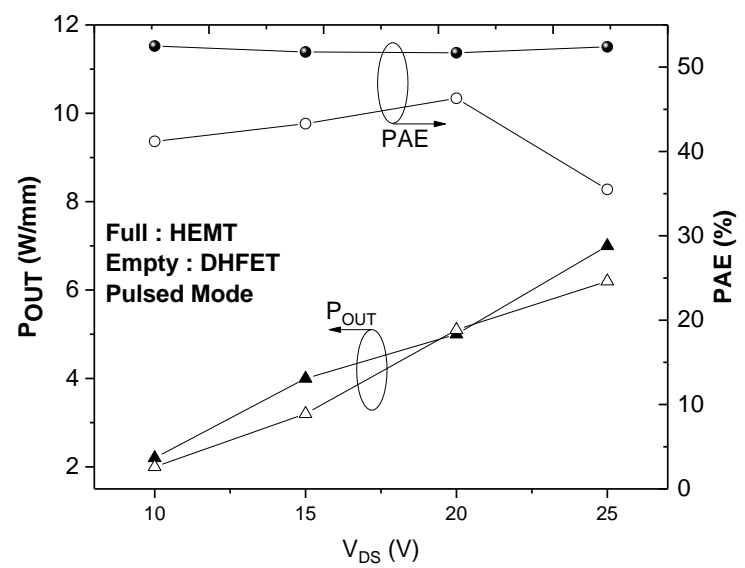


Fig. 8. Pulsed output power density (triangle) and PAE (circle) of both structures versus $\mathrm{V}_{\mathrm{DS}}$ at $40 \mathrm{GHz}$.

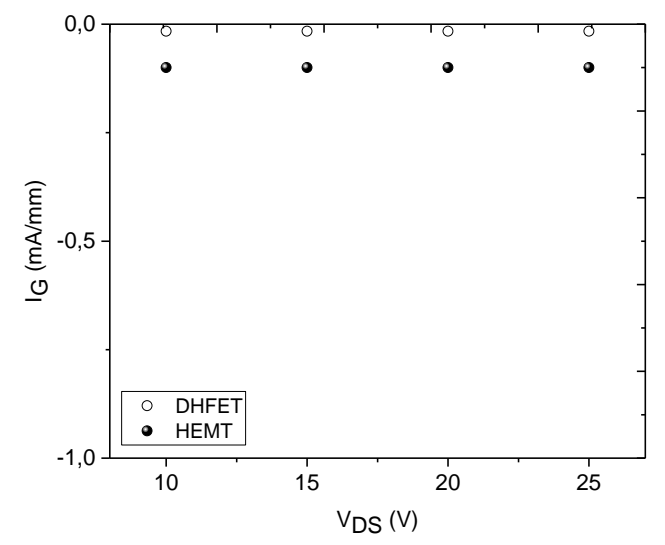

Fig. 9 Evolution of the gate leakage for the HEMTs (filled) and DHFETs (empty) at $40 \mathrm{GHz}$.

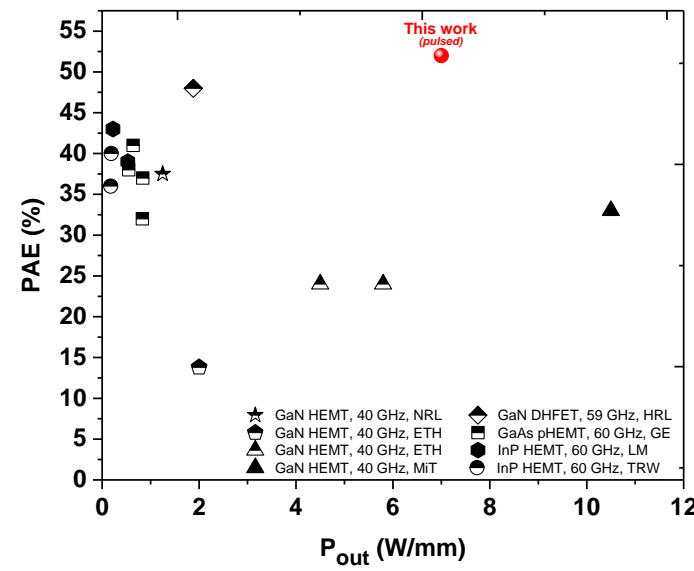

Fig. 10. Benchmark of peak PAE vs output RF power density for Q and V band [12], [15], [25]-[30].

\section{RAMAN THERMOGRAPHY MEASUREMENT}

The performance enhancement observed on the carbon-doped GaN HEMTs was attributed to a better thermal dissipation. To verify this statement, we assessed the channel temperature of these devices using Raman thermography [31]-[35]. These measurements 
were carried out on same dimensions $2 \times 50 \mu \mathrm{m}$ DHFET and HEMT GaN/SiC devices. Thermal shift of $\mathrm{E}_{\mathrm{g}}$ Raman peak of $\mathrm{TiO}_{2}$ nanoparticles (NP) [36] deposited on the device surface, with respect to a reference value at the device pinch-off, was used to determine device surface temperature. This was measured by confocal Renishaw InVia Raman microscope in backscattering configuration under $488 \mathrm{~nm}$ laser excitation. A schematic representation of Raman $\mathrm{TiO}_{2} \mathrm{NP}$ temperature measurement location, on top of the passivation at the drain edge of the gate is displayed in Fig. 11. A finite elements steadystate thermal model (Fig. 12) was subsequently calibrated with the measured surface temperature data and used for the junction temperature $\left(T_{\mathrm{J}}\right)$ extraction.

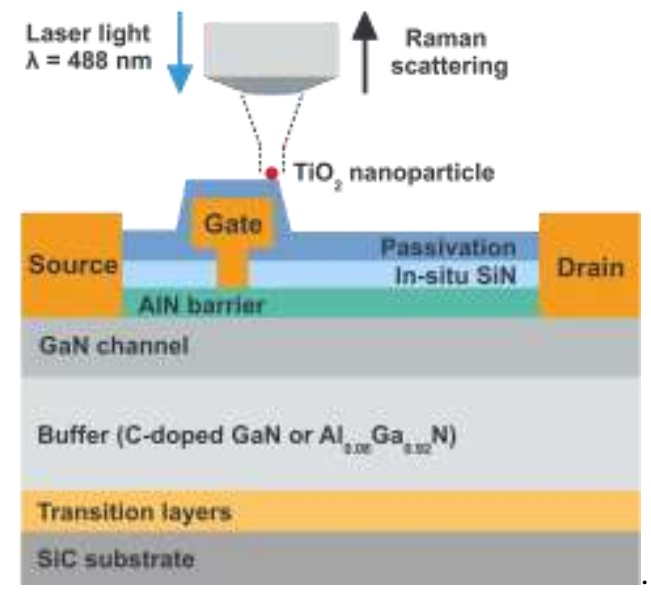

Fig. 11. Schematic representation of Raman $\mathrm{TiO}_{2} \mathrm{NP}$ temperature measurement.

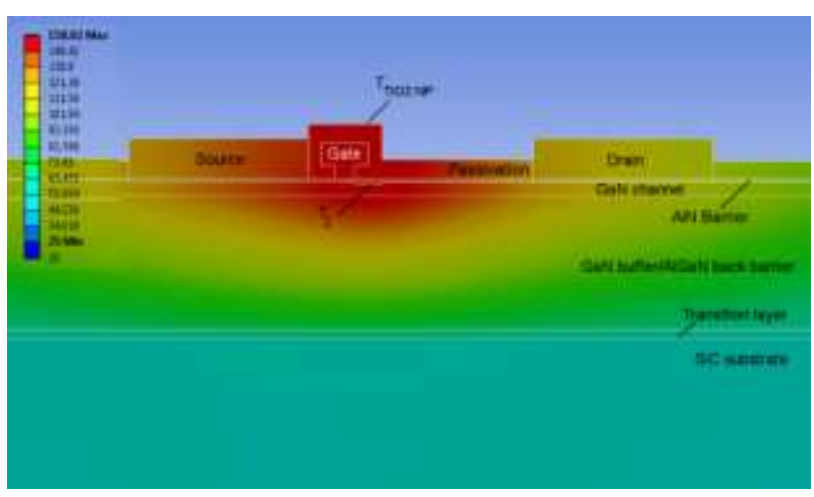

Fig. 12. Device thermal modeling fitted to the experimental data.

The determined peak junction temperatures are shown in Fig. 13. We note that the temperature rise difference between $\mathrm{T}_{\mathrm{TiO} 2} \mathrm{NP}$ and $\mathrm{T}_{\mathrm{J}}$ was $\sim 3.5 \%$ and $\sim 5.5 \%$ for the DHFET and the HEMT, respectively as the device surface is close to the highest temperature location in the device. As expected, the DHFET reached much higher $\mathrm{T}_{\mathrm{J}}$ (approaching $\sim 60 \%$ ) than the HEMT for $\mathrm{P}_{\text {diss }}>5 \mathrm{~W} / \mathrm{mm}$. The thermal resistance $\mathrm{R}_{\mathrm{TH}}=\Delta \mathrm{T} / \mathrm{P}_{\text {diss }}$ was extracted from the slope of fitted trend lines of $\mathrm{T}_{\mathrm{J}}$ vs $\mathrm{P}_{\text {diss. }}$. Overall, the results showed that 
$\mathrm{R}_{\mathrm{TH}}$ of the HEMT $\left(10^{\circ} \mathrm{C} \mathrm{mm} / \mathrm{W}\right)$ was $\sim 43 \%$ lower as compared to the DHFET $\left(17.5^{\circ} \mathrm{C}\right.$ $\mathrm{mm} / \mathrm{W}$ ) and comparable to reported values of $\mathrm{GaN}$ on $\mathrm{SiC}$ devices of similar dimensions [37], confirming the results we obtained from the electrical measurements.

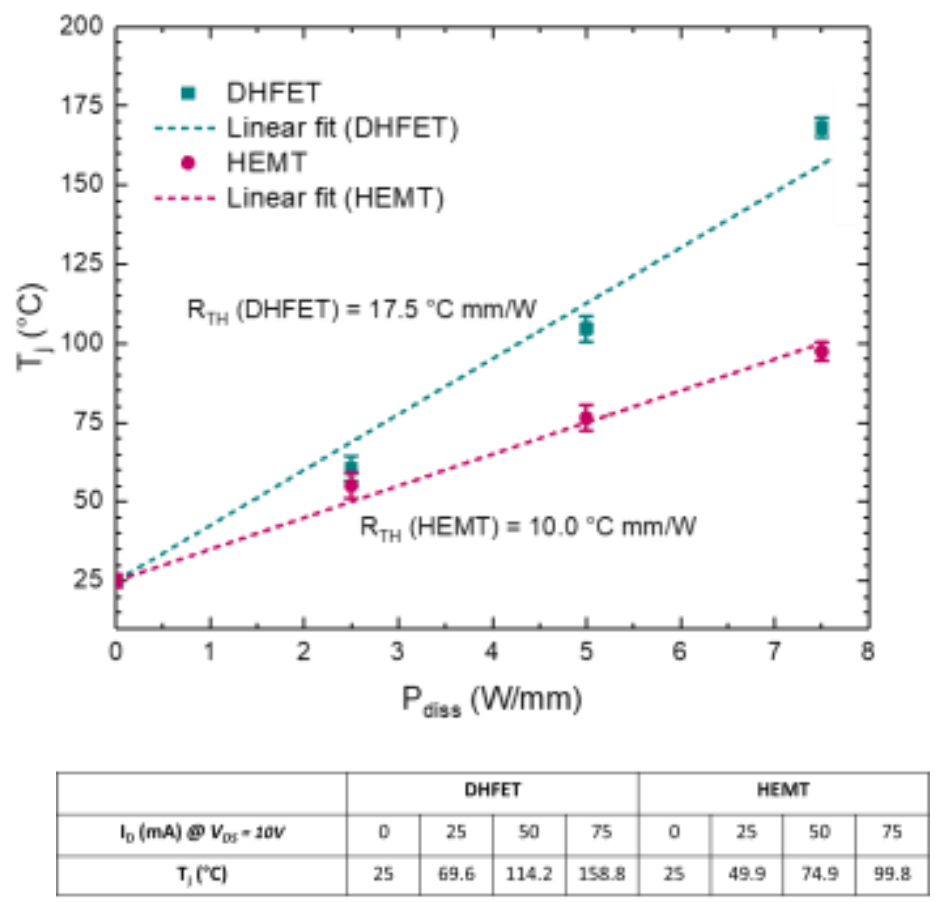

Fig. 13. Peak channel temperature of the HEMTs and DHFETs as a function of the dissipated power density.

The table specifies the current used for each extracted junction temperature.

\section{Conclusion}

This work shows that a careful architecture of buffer layers should be employed in order to perform high performance millimeter-wave $\mathrm{GaN}$ devices. The use of higher bias operation $\left(\mathrm{V}_{\mathrm{DS}} \geq 20 \mathrm{~V}\right)$ is possible when using deep sub-micrometer gate lengths only if the thermal resistance induced by the buffer layers is reduced. In particular, it is shown that a thick AlGaN back barrier (DHFET structure) with $8 \% \mathrm{Al}$ into the buffer results in a significant drop of the PAE at $\mathrm{V}_{\mathrm{DS}}>20 \mathrm{~V}$ even in pulsed mode. This is illustrated by a much higher thermal resistance (obtained by Raman Thermography measurements) as compared to the HEMT structure. The optimized AIN/GaN HEMT structure enabled to deliver a state-of-the-art combination of PAE (> 50\%) and an output power density of 7 $\mathrm{W} / \mathrm{mm}$ at $40 \mathrm{GHz}$ and $\mathrm{V}_{\mathrm{DS}}=25 \mathrm{~V}$. 


\section{Acknowledgments}

This research was funded and supported by the French RENATECH network and the French Defense Procurement Agency (DGA) under Project EDA-EuGaNiC and Contract FUI-VeGaN.

\section{References}

1. P. Saad, H. M. Nemati, M. Thorsell, K. Andersson, and C. Fager, "An inverse class-F GaN HEMT power amplifier with 78\% PAE at $3.5 \mathrm{GHz}$," Eur. Microw. Week 2009, EuMW 2009 Sci. Prog. Qual. Radiofreq. Conf. Proc. - 39th Eur. Microw. Conf. EuMC 2009, no. October, pp. 496-499, 2009, doi : 10.23919/EUMC.2009.5296560

2. J. S. Moon, R. Grabar, D. Brown, I. Alvarado-Rodriguez, D. Wong, A. Schmitz, H. Fung, P. Chen, J.-C. Kang, S. Kim, T. Oh, and C. Mcguire, " $>70 \%$ power-added-efficiency dual-gate, cascode GaN HEMTs without harmonic tuning," IEEE Electron Device Lett., vol. 37, no. 3, pp. 272-275, 2016, doi : 10.1109/LED.2016.2520488

3. B. Romanczyk, Steven Wienecke, Matthew Guidry, Haoran Li, Elaheh Ahmadi, Xun Zheng, Stacia Keller, and Umesh K. Mishra, "Demonstration of Constant $8 \mathrm{~W} / \mathrm{mm}$ Power Density at 10, 30, and $94 \mathrm{GHz}$ in State-of-the-Art Millimeter-Wave N-Polar GaN MISHEMTs," IEEE Trans. Electron Devices, vol. 65, no. 1, pp. 45-50, 2018, doi : 10.1109/TED.2017.2770087

4. K. Takagi, S. Takatsuka, Y. Kashiwabara, and S. Teramoto, "Ku-Band AlGaN/GaN-HEMT with over $30 \%$ of PAE," Engineering, pp. 457-460, 2009.

5. J. S. Moon, J. S. Moon, D. Wong, M. Hu, P. Hashimoto, M. Antcliffe, C. McGuire, M. Micovic, and P. Willadson, "55\% PAE and high power Ka-band GaN HEMTs with linearized transconductance via $\mathrm{n}+\mathrm{GaN}$ source contact ledge," IEEE Electron Device Lett., vol. 29, no. 8, pp. 834-837, 2008, doi : 10.1109/LED.2008.2000792

6. A. Crespo, M. M. Bellot, K. D. Chabak, J. K. Gillespie, G. H. Jessen, V. Miller, M. Trejo, G. D. Via, D. E. Walker, Jr., B. W. Winningham, H. E. Smith, T. A. Cooper, X. Gao, and S. Guo, "High-power Ka-band performance of AlInN/GaN HEMT with 9.8-nm-thin barrier," IEEE Electron Device Lett., vol. 31, no. 1, pp. 2-4, 2010, doi : 10.1109/LED.2009.2034875

7. M. Micovic, , D. F. Brown, A. Kurdoghlian, D. Santos, B. Grabar, J. Magadia, I. Khalaf, H. Y. Tai, E. Prophet, S. D. Burnham, J. C. Wong, D. Regan, H. H. Fung, and Y. Tang, "GaN DHFETs Having 48\% Power Added Efficiency and 57\% Drain Efficiency at V-band," IEEE Electron Device Lett., vol. 38, no. 12, pp. 1708-1711, 2017, doi : 10.1109/LED.2017.2763940

8. Y. Tang, K. Shinohara, D. Regan, A. Corrion, D. Brown, J. Wong, A. Schmitz, H. Fung, S. Kim, and M. Micovic., "Ultrahigh-Speed GaN High-Electron-Mobility Transistors With fT/fmax of 454/444 GHz," IEEE Electron Device Lett., vol. 36, no. 6, pp. 549-551, 2015, doi : 10.1109/LED.2015.2421311

9. F. Medjdoub, M. Zegaoui, B. Grimbert, N. Rolland, and P.-A. Rolland, "Effects of AlGaN Back Barrier on AlN/GaN-on-Silicon High-Electron-Mobility Transistors," Appl. Phys. Express, vol. 4, no. 12, p. 124101, Nov. 2011, doi : 10.1143/APEX.4.124101

10. D. F. Brown, A. Williams, K. Shinohara, A. Kurdoghlian, I. Milosavljevic, P. Hashimoto, R. Grabar, S. Burnham, C. Butler, P. Willadsen, and M. Micovic, "W-Band Power Performance of AlGaN/GaN DHFETs with Regrown n+ GaN Ohmic Contacts by MBE," pp. 461-464, 2011, doi : 10.1109/IEDM.2011.6131584

11. F. Medjdoub, M. Zegaoui, B. Grimbert, D. Ducatteau, N. Rolland, and P. A. Rolland, "First demonstration of high-power GaN-on-silicon transistors at $40 \mathrm{GHz}$," IEEE Electron Device Lett., vol. 33, no. 8, pp. 1168-1170, 2012, doi : 10.1109/LED.2012.2198192

12. E. Dogmus, R. Kabouche, A. Linge, E. Okada, M. Zegaoui, and F. Medjdoub, "High power, high PAE Q-band sub-10 barrier thickness AIN/GaN HEMTs ," Phys. Status Solid (a), 2017, doi : $\underline{10.1002 / \text { pssa.201600797 }}$ 
13. T. Palacios, A. Chakraborty, S. Rajan, C. Poblenz, S. Keller, S. P. DenBaars, J. S. Speck, and U. K. Mishra, "High-power AlGaN/GaN HEMTs for Ka-band applications," IEEE Electron Device Lett., vol. 26, no. 11, pp. 781-783, 2005, doi : 10.1109/LED.2005.857701

14. M. Micovic, P. Hashimoto, M. Hu, I. Milosavljevic, J. Duvall, P. J. Willadsen, W.- S. Wong, A. M. Conway, A. Kurdoghlian, P. W. Deelman, J.-S. Moon, A. Schmitz, and M. J. Delaney, "GaN Double Heterojunction Field Effect Transistor For Microwave and Millimeterwave Power Applications," IEEE International Electron Devices Meeting , pp. 807-810. 2004, doi : 10.1109/IEDM.2004.1419298

15. F. Medjdoub, B. Grimbert, D. Ducatteau, and N. Rolland, "Record Combination of PowerGain Cut-Off Frequency and Three-Terminal Breakdown Voltage for GaN-on-Silicon Devices," Appl. Phys. Express, vol. 6, no. 4, p. 44001, Apr. 2013.

16. W. Liu and A. A. Balandin, "Thermal conduction in AlxGa1-xN alloys and thin films," J. Appl. Phys., vol. 97, no. 7, pp. 1-6, 2005.

17. P. Moens, P. Vanmeerbeek, A. Banerjee, J. Guo , C. Liu , P. Coppens, A. Salih, M. Tack "On the Impact of Carbon-Doping on the Dynamic Ron and Off-state Leakage Current of 650V GaN Power Devices," IEEE 27th International Symposium on Power Semiconductor Devices \& IC's, pp. 37-40, 2015, doi : 10.1109/ISPSD.2015.7123383

18. M. J. Uren, J. Moreke, and M. Kuball, "Buffer design to minimize current collapse in GaN/AlGaN HFETs," IEEE Trans. Electron Devices, vol. 59, no. 12, pp. 3327-3333, 2012, doi : $\underline{\text { 10.1109/TED.2012.2216535 }}$

19. M. Kuball, J. M. Hayes, M. J. Uren, T. Martin, J. C. H. Birbeck, R. S. Balmer, and B. T. Hughes, "Measurement of Temperature in Active High-Power AlGaN/GaN HFETs Using Raman Spectroscopy," IEEE Electron Device Lett., vol. 23, no. 1, pp. 10-12, 2002, doi : $10.1109 / 55.974795$

20. R. Pecheux, R. Kabouche, E. Okada, M. Zegaoui, and F. Medjdoub, "C-doped AlN/GaN HEMTs for High efficiency $\mathrm{mmW}$ applications," International Workshop on Integrated Nonlinear Microwave and Millimetre-wave Circuits (INMMIC) pp. 31-33, 2018. doi : 10.1109/INMMIC.2018.8430021

21. R. Pecheux, R. Kabouche, E. Dogmus, A. Linge, E. Okada, M. Zegaoui, and F. Medjdoub "Importance of buffer configuration in GaN HEMTs for high microwave performance and robustness," ESSDERC, pp. 4-7, 2017, doi : 10.1109/ESSDERC.2017.8066633

22. J. Derluyn, S. Boeykens, K. Cheng, R. Vandersmissen, J. Das, W. Ruythooren, S. Degroote, M. R. Leys, M. Germain, and G. Borghs "Improvement of AlGaN/GaN high electron mobility transistor structures by in situ deposition of a $\mathrm{Si}_{3} \mathrm{~N}_{4}$ surface layer," J. Appl. Phys., vol. 98, no. 5, p. 54501, 2005, doi : https://doi.org/10.1063/1.2008388

23. D. Marcon, M. V. Hove, D. Visalli, J. Derluyn, J. Das, F. Medjdoub, S. Degroote, M. Leys, K. Cheng and R. Mertens, "Excellent Stability of GaN-on-Si High Electron Mobility Transistors with $5 \mu \mathrm{m}$ Gate-Drain Spacing Tested in Off-State at a Record Drain Voltage of $200 \mathrm{~V}$ and $200{ }^{\circ}$ C," Jpn. J. Appl. Phys., vol. 49, no. 4, p. 04DF07, Apr. 2010,

24. D. Marcon, F. Medjdoub, D. Visalli, M. V. Hove, J. Derluyn, J. Das, S. Degroote, M. Leys, K. Cheng, S. Decoutere, R. Mertens, M. Germain, and G. Borghs "High temperature on- and offstate stress of GaN-on-Si HEMTs with in-situ $\mathrm{Si}_{3} \mathrm{~N}_{4}$ cap layer," IEEE Int. Reliab. Phys. Symp. Proc., pp. 146-151, 2010, doi : 10.1109/IRPS.2010.5488836

25. R. Kabouche, E. Okada, E. Dogmus, A. Linge, M. Zegaoui, and F. Medjdoub, "Power Measurement Setup for On-Wafer Large Signal Characterization Up to Q-Band," IEEE Microw. Wirel. Components Lett., vol. 27, no. 4, pp. 419-421, 2017. doi : 10.1109/LMWC.2017.2678424

26. B. P. Downey, D. J. Meyer, D. S. Katzer, and J. A. Roussos, "SiN $/$ /InAlN/AlN/GaN MISHEMTs With $10.8 \mathrm{THz} \cdot \mathrm{V}$ Johnson Figure of Merit," IEEE Electron Device Lett., vol. 35, no. 5, pp. 527-529, 2014, doi : 10.1109/LED.2014.2313023

27. D. Marti, S. Tirelli, A. R. Alt, J. Roberts, and C. R. Bolognesi, " $150-\mathrm{GHz}$ cutoff frequencies and $2-\mathrm{W} / \mathrm{mm}$ output power at $40 \mathrm{GHz}$ in a millimeter-wave AlGaN/GaN HEMT technology on silicon," IEEE Electron Device Lett., vol. 33, no. 10, pp. 1372-1374, 2012, doi : 10.1109/LED.2012.2204855 
28. S. Tirelli, L. Lugani, D. Marti, J. F. Carlin, N. Grandjean, and C. R. Bolognesi, "AlInN-based HEMTs for large-signal operation at $40 \mathrm{GHz}$," IEEE Trans. Electron Devices, vol. 60, no. 10, pp. 3091-3098, 2013, doi : 10.1109/TED.2013.2262136

29. M. Kao, P. M. Smith, P. Ho,P.-C. Chao,K.H.G. Duh, A.A. Jabra and J.M. Ballingall "Very High Power-Added Efficiency and Low-Noise 0.15- $\mu \mathrm{m}$ Gate-Length Pseudomorphic HEMT's" IEEE Electron Device Lett., vol. I, no. 12, pp. 580-582, 1989, doi : $\underline{10.1109 / 55.43146}$

30. W. M. T. Kong, Sujane C. Wang, Pane-Chane Chao, Der-Wei Tu, Kuichul Hwang, O. S. A. Tang, Shih-Ming Liu, Pin Ho, Kirby Nichols, and John Heaton "Very high efficiency V-band power InP HEMT MMICs," IEEE Electron Device Lett., vol. 21, no. 11, pp. 521-523, 2000, doi : $\underline{10.1109 / 55.877196}$

31. R. Grundbacher, , R. Lai, M. Nishimoto, T. P. Chin, Y. C. Chen, M. Barsky, T. Block, and D. Streit "Pseudomorphic InP HEMT's with dry-etched source vias having $190 \mathrm{~mW}$ output power and 40\% PAE at V-band," IEEE Electron Device Lett., vol. 20, no. 10, pp. 517-519, 1999, doi : $10.1109 / 55.791928$

32. M. Kuball, and J. W. Pomeroy, "A Review of Raman Thermography for Electronic and OptoElectronic Device Measurement With Submicron Spatial and Nanosecond Temporal Resolution," IEEE Transactions on Device and Materials Reliability, vol. 16, no. 4, pp. 667684, 2016, doi : 10.1109/TDMR.2016.2617458

33. D. M. Risbud, K. Pedrotti, M. Power, J. W. Pomeroy, and M. Kuball, "Thermal characterization of high voltage GaN-on-Si Schottky Barrier Diodes (SBD) for designing an on-chip thermal shutdown circuit for a power HEMT," WiPDA, pp. 156-161, 2015, doi : 10.1109/WiPDA.2015.7369293

34. J. Pomeroy, M. Bernardonia, A. Saruaa, A. Manoia, D.C. Dumkab, D.M. Fanningb and M. Kuballa "Achieving the Best Thermal Performance for GaN-on-Diamond," 2013 IEEE Compound Semiconductor Integrated Circuit Symposium (CSICS), pp. 1-4, 2013, doi : $\underline{10.1109 / C S I C S .2013 .6659210}$

35. M. Power, James W. Pomeroy, Yohei Otoki, Takeshi Tanaka, Jiro Wada, Masaaki Kuzuhara, Wolfgang Jantz, Andrew Souzis, Martin Kuball "Measuring the thermal conductivity of the GaN buffer layer in AlGaN/GaN HEMTs," Phys. Status Solidi, 2015, vol. 212, no. 8, pp. 1742 1745, doi : 10.1002/pssa.201431788

36. Y.L. Du, Y. Deng, M .S. Zhang, "Variable-temperature Raman scattering study on anatase titanium dioxide nanocrystal, "Journal of Physics and Chemistry of Solids, Volume 67, Issue 11, 2006, Pages 2405-2408, ISSN 0022-3697

37. S Garcia, I Î́niguez-de-la-Torre, J Mateos, T González and S Pérez "Impact of substrate and thermal boundary resistance on the performance of AlGaN/GaN HEMTs analyzed by means of electro-thermal Monte Carlo simulations" Semicond. SCi. Technol. 201631065005 doi:10.1088/0268-1242/31/6/065005

38. J. Joh, J.A. del Alamo, U. Chowdhury, T. Chou, H. Tserng and J. L. Jimenez, "Measurement of Channel Temperature in GaN High-Electron Mobility Transistor, "IEEE Transactions on Electron Devices, Volume 56, Issue 12, 2009, Pages 2895-2901, doi : $\underline{10.1109 / T E D .2009 .2032614}$ 